\title{
A etnobotânica e o uso de plantas medicinais na Comunidade Barreirinho, Santo Antônio de Leverger, Mato Grosso, Brasil
}

\author{
Ethnobotany and the use of medicinal plants in the Barreirinho Community, \\ Santo Antônio de Leverger, Mato Grosso, Brazil \\ La etnobotánica y el uso de plantas medicinales en la Comunidad Barreirinho, \\ Santo Antônio de Leverger, Mato Grosso, Brasil
}

\author{
André Luís de Souza Ferreira ${ }^{1}$ \\ Maria Corette Pasa ${ }^{1}$ \\ Cecília Verônica Nunez ${ }^{2}$
}

DOI: http://dx.doi.org/10.20435/inter.v21i4.1924

\begin{abstract}
Resumo: Objetivou-se investigar e resgatar o conhecimento tradicional acerca dos recursos vegetais, 0 manejo, o preparo e a indicação terapêutica das plantas medicinais utilizadas na Comunidade Barreirinho, Santo Antônio de Leverger, Mato Grosso (MT). O estudo qualitativo e quantitativo utilizou pré-teste, observação direta, turnê guiada, entrevistas e frequência absoluta e relativa. Identificaram-se 141 espécies medicinais, pertencentes a 60 famílias botânicas, e, entre elas, Fabaceae, Lamiaceae e Asteraceae foram as mais representativas.
\end{abstract}

Palavras-chave: traditional knowledge; plant resources; phytotherapy.

Abstract: The objective was to investigate and recover the traditional knowledge about the vegetal resources, the management, the preparation, and the therapeutic indication of the medicinal plants used in the Barreirinho Community, Santo Antônio de Leverger, Mato Grosso (MT). The qualitative and quantitative study used the pre-test, direct observation, guided tour, interviews, absolute and relative frequencies. It was identified 141 medicinal species, belonging to 60 botanical families, and, among them, Fabaceae, Lamiaceae, and Asteraceae were the most representative.

Keywords: Regional development indicator (IDR); regions of Tocantins; social and economic inequalities.

Resumen: Se pretendió investigar y rescatar el conocimiento tradicional sobre los recursos vegetales, el manejo, la preparación y la indicación terapéutica de las plantas medicinales utilizadas en la Comunidad Barreirinho, Santo Antônio de Leverger, Mato Grosso (MT). El estudio cualitativo y cuantitativo utilizó pre-test, observación directa, gira guiada, entrevistas, frecuencias absolutas y relativas. Se identificaron 141 especies medicinales, pertenecientes a 60 familias botánicas, y, entre ellas, Fabaceae, Lamiaceae y Asteraceae fueron las más representativas.

Palabras claves: saber tradicional; recursos vegetales; fitoterapia.

\section{INTRODUÇÃO}

Os recursos vegetais disponíveis na natureza, há muito tempo, têm sido aproveitados pelo homem, fornecendo elementos essenciais para a manutenção da vida humana e mesmo de todos os outros organismos. Esses recursos podem ser utilizados para as mais diversas finalidades, como alimentação, construção, remédios, ornamentação, entre outros (GUARIM NETO; PASA, 2009).

Nesse contexto, a etnobotânica surge como uma ciência que estuda as sociedades humanas, passadas e presentes, e suas interações ecológicas, genéticas, evolutivas, simbólicas e culturais com as plantas (ALEXIADES, 1999).

Desse modo, o resgate etnobotânico e a valorização do saber empírico permitem

\footnotetext{
${ }^{1}$ Universidade Federal de Mato Grosso (UFMT), Cuiabá, Mato Grosso, Brasil.

${ }^{2}$ Instituto Nacional de Pesquisas da Amazônia (Inpa), Manaus, Amazonas, Brasil.
} 
compreender o aproveitamento e a interação do homem com a natureza vegetal, bem como resgatar informações sobre os usos tradicionais e suas potencialidades. Além disso, possibilitam registrar a composição florística local, o manejo e as etnocategorias de usos das plantas.

Assim como a etnobotânica, a etnofarmacologia busca conhecer e compreender, de modo mais aprofundado, o uso das plantas, por meio de uma exploração científica do uso tradicional, desde as formas de manejo até as formas de preparo de remédios, dose, indicação terapêutica, ou seja, todas as informações necessárias para favorecer o estudo científico (ELISABETSKY, 2003).

O saber tradicional sobre a utilização das plantas, principalmente para usos medicinais, contextualizado cultural e ambientalmente, tem sido foco de diversos estudos em diferentes áreas do conhecimento.

Assim, as observações sobre o uso e a eficácia de plantas popularmente consideradas como medicinais contribuem de forma relevante para a divulgação das virtudes terapêuticas dos vegetais pelos efeitos medicinais que produzem, apesar de não terem seus constituintes químicos conhecidos. Dessa forma, usuários de plantas medicinais de todo o mundo mantêm em voga a prática do consumo de fitoterápicos, tornando válidas as informações terapêuticas que foram sendo acumuladas durante séculos (COSTA; SILVA, 2014).

No Brasil, a utilização de plantas no tratamento de doenças apresenta influência da cultura indígena, africana e, naturalmente, europeia. Essas influências deixaram marcas profundas nas diferentes áreas da cultura brasileira, tanto no aspecto material como no espiritual. Elas constituem a base da medicina popular que, há algum tempo, vem sendo retomada pela medicina natural, procurando resgatar suas práticas, dando-Ihes caráter científico e integrando-as num conjunto de princípios que visam não apenas curar algumas doenças, mas restituir o ser humano à vida natural (BARROS et al., 2010).

Com base nas informações apresentadas, este estudo tem por objetivo resgatar o conhecimento tradicional acerca dos recursos vegetais, o manejo, o preparo e a indicação terapêutica das plantas medicinais utilizadas na Comunidade Barreirinho, Santo Antônio de Leverger, Mato Grosso, Brasil.

\section{METODOLOGIA}

O estudo foi realizado na Comunidade Barreirinho, localizada no município de Santo Antônio de Leverger, Mato Grosso, MT (Região Metropolitana do Vale do Rio Cuiabá), rodovia MT-040, km 20 ao sul de Cuiabá. A comunidade encontra-se circunscrita pelas coordenadas de latitude $15^{\circ} 48^{\prime} 30^{\prime \prime}$ Sul e longitude 56 01'30" Oeste, na porção Centro-Sul do Estado de Mato Grosso, estabelecida à margem direita do Rio Cuiabá.

Segundo classificação de Koppen e Geiger, a região tem o clima (Aw) predominantemente tropical com estação seca, apresentando duas estações distintas e bem definidas, uma chuvosa, de outubro a março, e outra seca, de abril a setembro. A temperatura média anual em Santo Antônio de Leverger é de $26,1^{\circ} \mathrm{C}$, e $1.267 \mathrm{~mm}$ é a pluviosidade média anual (INSTITUTO BRASILEIRO DE GEOGRAFIA E ESTATÍSTICA [IBGE], 2010).

O procedimento metodológico da pesquisa abordou tratamentos qualitativos e quantitativos. Segundo Minayo (2007), a análise qualitativa leva em consideração os níveis mais profundos das relações sociais, operacionalizando-os por meio dos aspectos subjetivos, visando compreender a lógica interna de grupos, instituições e atores quanto aos valores culturais e representações. O tratamento quantitativo utilizou a frequência absoluta e relativa para a análise dos dados. 
O estudo foi exposto aos informantes e os que aceitaram participar de forma livre e espontânea assinaram o Termo de Consentimento Livre e Esclarecido (TCLE) requerido de MS - Resolução 196/96, aprovado pelo CEP/UFMT/UFSC (18847013.0.0000.0121 de 18.08.13) e Iphan (01450.012607/2013-20) para o Grupo de Pesquisa (DGP) Estudando o Cerrado (Escer) Comunidades Tradicional e Quilombola.

A coleta de dados socioeconômicos e etnobotânicos foi realizada mediante o emprego das técnicas metodológicas como o pré-teste (diagnóstico), observação direta, turnê guiada e entrevistas dos tipos semiestruturada e aberta (MINAYO, 1994). As entrevistas ocorreram no período de março de 2016 a março de 2017, totalizando 45 informantes residentes da comunidade local. As entrevistas abrangem informações socioeconômicas sobre idade, sexo, religião, atividade profissional, escolaridade, renda familiar, cor, número de pessoas que compõem a família, além de informações sobre o imóvel, o quintal, e em relação ao hábitos e estado de saúde.

O registro das entrevistas foi realizado por meio de um gravador digital portátil complementado por um diário de campo, para registrar informações pertinentes à pesquisa, e uma máquina fotográfica digital, para registrar e armazenar imagens que envolvem o manejo com as plantas.

As plantas utilizadas e/ou cultivadas foram coletadas para identificação e comparação junto ao herbário da Universidade Federal de Mato Grosso, e os nomes científicos e suas respectivas famílias botânicas foram classificadas de acordo com o sistema de taxonomia vegetal APG IV (ANGIOSPERM PHYLOGENY GROUP, 2016).

\section{RESULTADOS E DISCUSSÕES}

\subsection{Dados socioeconômicos}

Foram entrevistados 45 indivíduos, sendo 26 homens e 19 mulheres. Na Comunidade Barreirinho, é comum os homens e as mulheres terem contato com a flora local e com atividades realizadas no quintal, como roça, cultivo e manejo com as plantas, cuidados com o lar, os filhos e/ ou netos. Pasa et al. (2015) e Gonçalves e Pasa (2015) obtiveram resultados para as comunidades de Mata Cavalo (Nossa Senhora do Livramento, MT) e Sucuri (Cuiabá, MT), respectivamente, onde a maioria dos entrevistados do sexo feminino justifica ser responsável pelas atividades do lar e cuidados com os filhos e netos, proporcionando a permanência da mulher na residência.

Dos entrevistados, 40\% nasceram em Santo Antônio de Leverger, sendo que a maioria (47\%) mora há mais de 20 anos na Comunidade Barreirinho. O Estado de Mato Grosso foi o estado de origem mais expressivo entre os moradores, estes oriundos do Distrito de Mimoso e de Cuiabá. Entre outros estados de origem, foram mencionados Ceará, Bahia, Paraná e Paraíba. Entre os entrevistados, 60\% são de origem rural e 32\% afirmaram ser descendentes de índios.

A faixa etária variou entre 19 e 85 anos, tendo como representante da idade mais avançada uma pessoa do sexo feminino. No estudo de Moreira e Guarim Neto (2015) realizado em 2013, em três bairros do município de Tangará da Serra, Estado de Mato Grosso, obtiveram-se resultados cuja faixa etária dos informantes variou entre 18 e 89 anos de idade. A faixa etária predominante entre os informantes foi entre 41 e 70 anos de idade para os homens.

Sobre a religiosidade, 64\% disseram ser católicos, seguidos por evangélicos, com 22\%; espíritas, com 4\%; e dois entrevistados relataram não pertencer a nenhuma religião. A cor da pele ou raça não teve diferença significativa, obtendo um resultado de 47\%, 38\% e $8 \%$ para brancos, 
negros e índios, respectivamente.

A renda familiar mensal chega no máximo a 1.500 reais ( $84 \%$ dos entrevitados), e em $44 \%$ das residências moram mais que quatro pessoas. Quanto à escolaridade dos entrevistados, essa variou de não escolarizado até o ensino superior, com ênfase para o ensino fundamental completo, com aproximadamente 35\%; ensino médio, com 33\%; e $7 \%$ sem escolarização.

O trabalho no lar é a principal atividade, realizada por $44 \%$ dos entrevistados (tanto para as mulheres como para os homens); $35 \%$ trabalham com a agricultura familiar e $18 \%$ pertencem à classe dos aposentados. Outros tipos de ocupação citados foram: comércio (tanto na comunidade rural como na cidade), vigilante, diarista, pedreiro, eletricista, enfermeira, entre outros.

Referindo-se ao estado de saúde dos informantes e seus hábitos, pode-se identificar que 33\% deles têm algum tipo de doença crônica, como hipertensão arterial, diabetes, gastrite e problemas na próstata. A comunidade tem assistência médica, porém o atendimento pelo médico acontece a cada 15 dias ou uma vez ao mês e apenas um técnico/enfermeiro atende todos os dias (segunda a sexta-feira).

Das residências da comunidade, todas são de alvenaria, com energia elétrica em cem por cento delas. A comunidade conta apenas com um poço artesiano comunitário (água salobra), alguns moradores dispõem de poços semiartesianos (água doce) e o esgotamento sanitário é do tipo fossa negra construída nas residências. Os imóveis, conforme os entrevistados, são próprios, sendo alguns adquiridos como herança de família.

\subsection{A Etnocategoria Medicinal}

Foi registrado na Comunidade Barreirinho um total de 141 espécies vegetais medicinais, distribuídas em 60 famílias botânicas. As mais citadas, conforme registrado na Tabela 1, foram o limão (Citrus x limon [L.] Osbeck), com 71,11\% das citações; o boldo (Plectranthus barbatus Andrews), com 68,89\%; a camomila (Chamomilla recutita [L.] Rauschert, com 64,44\%; o melãode-são-caetano (Momordica charantia L.), com 60\%; aroeira (Myracrodruon urundeuva [Allemão] Engl.), com 60\%; mangava-brava (Lafoensia pacari A.St.-Hil.), com 57,78\%; assa-peixe (Vernonia polyanthes Less.), com 55,56\%; eucalipto (Eucalyptus citriodora Hook.), com 53,33\%; babosa (Aloe vera L.), romã (Punica granatum L.) com 51,11\%. Ferreira, Batista e Pasa (2015), em Nossa Senhora do Livramento, MT, obtiveram resultados para o boldo com 91\% de representatividade. As famílias botânicas mais expressivas nas citações da etnocategoria medicinal foram: Fabaceae, Lamiaceae e Asteraceae.

A utilização de plantas medicinais na Comunidade Barreirinho é praticada por todos os entrevistados, desde os mais antigos até os mais jovens, contribuindo, assim, para a preservação da cultura do uso de plantas para essa finalidade na comunidade local. De acordo com Moreira e Guarim Neto (2015), a facilidade ao cultivo de plantas medicinais e o uso dessa medicina popular para combate de algum tipo de doença justificam seu uso entre as populações que utilizam desse recurso para alívio de alguma enfermidade, como dor e mal-estar, por exemplo.

$\mathrm{Na}$ Tabela 1, são apresentadas as espécies medicinais utilizadas na Comunidade Barreirinho, em que são informados nome popular, nome científico, parte da planta usada, formas de uso, doenças mais citadas e o número de citações. A folha foi a parte do vegetal mais citada e utilizada para tratamentos terapêuticos, com 110 indicações (equivalente a 53,40\%); seguida pelo uso do fruto, com 24 indicações (equivalente a 
11,65\%); e raízes, cascas, caules, sementes, flores e tubérculos, totalizando 44 indicações (equivalente a 21,36\%). Esses resultados estão de acordo com os estudos realizados por Pasa (2004), Pinto, Amorozo e Furlan (2006), Amaral e Silva (2008), Guarim Neto e Carvalho (2011), Moreira e Guarim Neto (2015), em que os seus respectivos estudos relatam a folha como órgão mais utilizado por quem pratica a automedicação a partir de fitoterápicos.

No que diz respeito ao preparo dos remédios caseiros, o chá ou infusão (107 indicações, equivalente a 51,94\%) foi a forma mais utilizada pelos entrevistados. Outras formas de preparo incluem maceração, decocção, compressa, queimada, curtir no vinho (garrafada) ou de molho na água, ferver e bater no leite e in natura. Nessa abordagem sobre o preparo de remédios a partir de plantas medicinais, Guarim Neto e Maciel (2008, p. 112) destacam que "[...] a humanidade busca nas plantas alívio para seus males corporais ou espirituais já há muito tempo, seja através dos chás, banhos unguentos ou tinturas caseiras".

Toledo e Barrera-Bassols (2009) relataram que cada indivíduo, dentro de seu cenário, molda um conjunto de experiências, resultando em três fontes preciosas de informações: "o que lhe disseram" (experiência histórica acumulada), "o que Ihe dizem" (experiência compartilhada) e, por fim, "o que se observa por si mesmo", que se trata da experiência individual de cada um. Pasa (2011, p. 186) também salienta que "a crença nos efeitos de cura pelas plantas usadas como medicinais varia entre as pessoas". Desse modo, observa-se neste estudo uma forte atenção dos informantes no uso das espécies vegetais, principalmente as medicinais. Esses sedimentaram um conhecimento que é muito importante para a cultura de uma comunidade ou um povo, como é parte da história de vida de cada um deles.

Tabela 1 - Espécies medicinais utilizadas na Comunidade Barreirinho, Santo Antônio de Leverger, MT, 2016

\begin{tabular}{|c|c|c|c|c|c|}
\hline Nome popular & Nome científico & Parte usada & Formas de uso & $\begin{array}{l}\text { Doenças mais } \\
\text { citadas }\end{array}$ & NC \\
\hline Limão & $\begin{array}{l}\text { Citrus x limon (L.) } \\
\text { Osbeck }\end{array}$ & $\begin{array}{l}\text { Folhas e } \\
\text { fruto }\end{array}$ & $\begin{array}{l}\text { Infusão, suco, } \\
\text { xarope }\end{array}$ & $\begin{array}{l}\text { Gripe, tosse e } \\
\text { cólica }\end{array}$ & 32 \\
\hline Boldo & $\begin{array}{l}\text { Plectranthus barbatus } \\
\text { Andr. }\end{array}$ & Folhas & $\begin{array}{l}\text { Infusão, maceração, } \\
\text { in natura }\end{array}$ & Estômago & 31 \\
\hline Manga & Mangifera indica L. & $\begin{array}{l}\text { Folhas e } \\
\text { fruto }\end{array}$ & Infusão & $\begin{array}{l}\text { Tosse, gripe e } \\
\text { bronquite }\end{array}$ & 29 \\
\hline Camomila & $\begin{array}{l}\text { Chamomilla recutita (L.) } \\
\text { Rauschert. }\end{array}$ & Folhas & Infusão & $\begin{array}{l}\text { Calmante e dor } \\
\text { no estômago }\end{array}$ & 29 \\
\hline $\begin{array}{l}\text { Melão-de-são- } \\
\text { caetano }\end{array}$ & Momordica charantia L. & Folhas & Infusão, maceração & Gripe e dengue & 27 \\
\hline Aroeira & $\begin{array}{l}\text { Myracrodruon urundeuva } \\
\text { (Allemão) Engl. }\end{array}$ & Cascas & $\begin{array}{l}\text { Garrafada, } \\
\text { decocção, melaço }\end{array}$ & $\begin{array}{l}\text { Cicatrização, } \\
\text { fraturas e tosse }\end{array}$ & 27 \\
\hline $\begin{array}{l}\text { Mangava- } \\
\text { brava }\end{array}$ & $\begin{array}{l}\text { Lafoensia pacari A. St.- } \\
\text { Hil. }\end{array}$ & Cascas & $\begin{array}{l}\text { Garrafada, molho } \\
\text { na água }\end{array}$ & Estômago & 26 \\
\hline Assa-peixe & $\begin{array}{l}\text { Vernonia polyanthes } \\
\text { Less. }\end{array}$ & Folhas e raiz & Infusão & $\begin{array}{l}\text { Tosse, gripe e } \\
\text { câncer }\end{array}$ & 25 \\
\hline Eucalipto & $\begin{array}{l}\text { Eucalyptus citriodora } \\
\text { Hook. }\end{array}$ & Folhas & $\begin{array}{l}\text { Infusão, garrafada, } \\
\text { decocção }\end{array}$ & $\begin{array}{l}\text { Febre, bronquite } \\
\text { e tosse }\end{array}$ & 24 \\
\hline Babosa & Aloe vera $\mathrm{L}$. & Folhas & In natura & $\begin{array}{l}\text { Cicatrizante e } \\
\text { queimaduras }\end{array}$ & 24 \\
\hline
\end{tabular}




\begin{tabular}{|c|c|c|c|c|c|}
\hline Nome popular & Nome científico & Parte usada & Formas de uso & $\begin{array}{l}\text { Doenças mais } \\
\text { citadas }\end{array}$ & NC \\
\hline Romã & Punica granatum L. & Fruto & $\begin{array}{l}\text { Infusão, garrafa, } \\
\text { decocção }\end{array}$ & $\begin{array}{l}\text { Inflamação na } \\
\text { garganta }\end{array}$ & 23 \\
\hline Guiné & Petiveria alliacea L. & Folhas & Infusão & $\begin{array}{l}\text { Inflamação na } \\
\text { garganta }\end{array}$ & 23 \\
\hline Arruda & Ruta graveolens L. & Folhas & Infusão & Dor de cabeça & 23 \\
\hline Quina & $\begin{array}{l}\text { Strychnos pseudoquina } \\
\text { A. St.-Hil. }\end{array}$ & Cascas & $\begin{array}{l}\text { Garrafada, } \\
\text { queimada }\end{array}$ & Inflamação & 22 \\
\hline Erva-cidreira & $\begin{array}{l}\text { Lippia alba (Mill.) } \\
\text { N. E. Br. ex P. Wilson }\end{array}$ & Folhas & Infusão & $\begin{array}{l}\text { Calmante e } \\
\text { hipertensão }\end{array}$ & 21 \\
\hline Acerola & Malpighia glabra L. & $\begin{array}{l}\text { Folhas e } \\
\text { fruto }\end{array}$ & Infusão, in natura & $\begin{array}{l}\text { Gripe e } \\
\text { bronquite }\end{array}$ & 21 \\
\hline $\begin{array}{l}\text { Erva-de-santa- } \\
\text { maria/mastruz }\end{array}$ & $\begin{array}{l}\text { Chenopodium } \\
\text { ambrosioides L. }\end{array}$ & Folhas & Maceração & Verminose & 21 \\
\hline Jamelão & $\begin{array}{l}\text { Syzygium cumini (L.) } \\
\text { Skeels }\end{array}$ & Folhas & Infusão & $\begin{array}{l}\text { Diabetes e } \\
\text { hipertensão }\end{array}$ & 21 \\
\hline Capim-cidreira & $\begin{array}{l}\text { Cymbopogon citratus } \\
\text { (DC.) Stapf }\end{array}$ & Folhas & Infusão & $\begin{array}{l}\text { Calmante e } \\
\text { hipertensão }\end{array}$ & 20 \\
\hline Caju & $\begin{array}{l}\text { Anacardium occidentale } \\
\text { L. }\end{array}$ & $\begin{array}{l}\text { Pseudofruto } \\
\text { e semente }\end{array}$ & In natura, decocção & $\begin{array}{l}\text { Cicatrização e } \\
\text { colesterol }\end{array}$ & 20 \\
\hline Terramicina & $\begin{array}{l}\text { Alternanthera brasiliana } \\
\text { (L.) Kuntze }\end{array}$ & Folhas & $\begin{array}{l}\text { Infusão, maceração, } \\
\text { decocção }\end{array}$ & $\begin{array}{l}\text { Inflamação, } \\
\text { infecção e } \\
\text { cicatrizante }\end{array}$ & 19 \\
\hline Erva-doce & Pimpinella anisum L. & Semente & Infusão & $\begin{array}{l}\text { Calmante e } \\
\text { hipertensão }\end{array}$ & 19 \\
\hline Tarumã & $\begin{array}{l}\text { Vitex megapotamica } \\
\text { (Sprengel) Moldenke }\end{array}$ & Folhas & Infusão & $\begin{array}{l}\text { Diabetes e } \\
\text { hipertensão }\end{array}$ & 19 \\
\hline Hortelãzinho & Mentha crispa L. & Folhas & Infusão & Tosse e gripe & 17 \\
\hline Noni & Morinda citrifolia L. & $\begin{array}{l}\text { Folhas e } \\
\text { fruto }\end{array}$ & $\begin{array}{l}\text { Infusão, in natura, } \\
\text { garrafada }\end{array}$ & $\begin{array}{l}\text { Diabetes, } \\
\text { infecção e câncer }\end{array}$ & 17 \\
\hline Erva-de-bicho & $\begin{array}{l}\text { Polygonum cf. } \\
\text { punctatum Elliott }\end{array}$ & $\begin{array}{c}\text { Folhas, cascas } \\
\text { e caule }\end{array}$ & Infusão & Febre & 17 \\
\hline Alho & & Bulbo & Decocção, garrafada & $\begin{array}{l}\text { Hipertensão, } \\
\text { gripe e infecção }\end{array}$ & 16 \\
\hline Pimenta & Capsicum frutescens $\mathrm{L}$. & Fruto & In natura & Dor e infecção & 16 \\
\hline Laranjeira & $\begin{array}{l}\text { Citrus sinensis (L.) } \\
\text { Osbeck }\end{array}$ & $\begin{array}{l}\text { Folhas e } \\
\text { fruto }\end{array}$ & Infusão, suco & $\begin{array}{l}\text { Calmante, } \\
\text { laxante e febre }\end{array}$ & 16 \\
\hline Alecrim & Rosmarinus officinalis L. & Folhas & Infusão, garrafada & $\begin{array}{l}\text { Dor de cabeça e } \\
\text { estômago }\end{array}$ & 16 \\
\hline Pequi & $\begin{array}{l}\text { Caryocar brasiliense A. } \\
\text { St.-Hil. }\end{array}$ & $\begin{array}{l}\text { Folhas e } \\
\text { fruto }\end{array}$ & Infusão & $\begin{array}{l}\text { Diabetes e } \\
\text { hipertensão }\end{array}$ & 16 \\
\hline Embaúba & $\begin{array}{l}\text { Cecropia pachystachya } \\
\text { Trécul. }\end{array}$ & Folhas e raiz & Infusão & $\begin{array}{l}\text { Tosse e } \\
\text { inflamação na } \\
\text { garganta }\end{array}$ & 16 \\
\hline Abóbora & $\begin{array}{l}\text { Cucurbita maxima } \\
\text { Duchesne ex Lam. }\end{array}$ & $\begin{array}{l}\text { Folhas, flor e } \\
\text { semente }\end{array}$ & $\begin{array}{l}\text { Maceração, in } \\
\text { natura }\end{array}$ & Dor de ouvido & 15 \\
\hline
\end{tabular}




\begin{tabular}{|c|c|c|c|c|c|}
\hline Nome popular & Nome científico & Parte usada & Formas de uso & $\begin{array}{l}\text { Doenças mais } \\
\text { citadas }\end{array}$ & NC \\
\hline Canela & $\begin{array}{l}\text { Cinnamomum } \\
\text { zeylanicum Breyne }\end{array}$ & Cascas & Decocção, garrafada & $\begin{array}{l}\text { Afrodisíaco, } \\
\text { tosse e gripe }\end{array}$ & 14 \\
\hline Algodão & Gossypium hirsutum L. & Folhas & Infusão, tintura & Inflamação & 14 \\
\hline Goiabeira & Psidium guajava L. & Fruto & In natura & Constipação & 14 \\
\hline Vassourinha & Scoparia dulcis L. & $\begin{array}{l}\text { Folhas e } \\
\text { caule }\end{array}$ & Infusão & Cicatrização & 14 \\
\hline Quebra-pedra & Phyllanthus niruri L. & Folhas & Infusão & Rins & 14 \\
\hline Cansanção & Jatropha urens L. & Folhas e raiz & Infusão & $\begin{array}{l}\text { Diabetes, } \\
\text { extração de } \\
\text { dentes }\end{array}$ & 13 \\
\hline Cebola & Allium cepa $\mathrm{L}$. & Bulbo & In natura, garrafada & $\begin{array}{l}\text { Gripe e } \\
\text { resfriado }\end{array}$ & 13 \\
\hline Lixeira & Curatella americana $\mathrm{L}$. & $\begin{array}{l}\text { Folhas, } \\
\text { cascas e raiz }\end{array}$ & Infusão, decocção & $\begin{array}{l}\text { Cicatrização e } \\
\text { tosse }\end{array}$ & 13 \\
\hline Hortelã & Mentha $\times$ villosa Huds. & Folhas & Infusão, in natura & $\begin{array}{l}\text { Gripe e } \\
\text { resfriado }\end{array}$ & 13 \\
\hline Pata-de-vaca & Bauhinia ungulata $\mathrm{L}$. & Folhas & Infusão & $\begin{array}{l}\text { Diabetes e } \\
\text { diurético }\end{array}$ & 13 \\
\hline Colônia & $\begin{array}{l}\text { Alpinia speciosa (J. C. } \\
\text { Wendl.) K. Schum. }\end{array}$ & Folhas & Infusão & $\begin{array}{l}\text { Calmante e } \\
\text { hipertensão }\end{array}$ & 13 \\
\hline $\begin{array}{l}\text { Nó-de- } \\
\text { cachorro }\end{array}$ & $\begin{array}{l}\text { Heteropterys } \\
\text { aphrodisiaca O. Mach. }\end{array}$ & Cascas & Infusão, garrafada & $\begin{array}{l}\text { Cicatrizante e } \\
\text { depurativo do } \\
\text { sangue }\end{array}$ & 13 \\
\hline Paratudo & $\begin{array}{l}\text { Tabebuia caraiba (Mart.) } \\
\text { Bureau }\end{array}$ & Folhas e raiz & $\begin{array}{l}\text { Infusão, decocção, } \\
\text { garrafada }\end{array}$ & $\begin{array}{l}\text { Anemia, } \\
\text { bronquite, dor, } \\
\text { câncer }\end{array}$ & 13 \\
\hline Jatobá & $\begin{array}{l}\text { Hymenaea stigonocarpa } \\
\text { Mart. ex Hayne }\end{array}$ & Fruto & Infusão, decocção & $\begin{array}{l}\text { Tosse, } \\
\text { bronquite e } \\
\text { pneumonia }\end{array}$ & 13 \\
\hline Manjericão & Ocimum minimum L. & Folhas & Infusão, in natura & Sinusite e gripe & 12 \\
\hline Dipirona & Achillea millefolium L. & Folhas & Infusão & Dor e febre & 12 \\
\hline Gengibre & $\begin{array}{l}\text { Zingiber officinale } \\
\text { Roscoe. }\end{array}$ & Rizoma & Decocção, garrafada & $\begin{array}{l}\text { Gripe, sinusite } \\
\text { e tosse }\end{array}$ & 12 \\
\hline Cravo & $\begin{array}{l}\text { Syzygium aromaticum } \\
\text { (L.) Merr. \& L. M. Perry }\end{array}$ & Flor & Decocção, garrafada & $\begin{array}{l}\text { Garganta, tosse, } \\
\text { dor de dente }\end{array}$ & 12 \\
\hline Gervão & $\begin{array}{l}\text { Stachytarpheta aff. } \\
\text { cayennensis (Rich.) Vahl. }\end{array}$ & Folhas e raiz & Infusão & Inflamação & 12 \\
\hline Copaíba & $\begin{array}{l}\text { Copaifera langsdorffii } \\
\text { Desf. }\end{array}$ & Folhas e raiz & Garrafada & $\begin{array}{l}\text { Inflamação, } \\
\text { tuberculose e } \\
\text { câncer }\end{array}$ & 12 \\
\hline Seriguela & Spondias purpurea $\mathrm{L}$. & $\begin{array}{l}\text { Folhas e } \\
\text { fruto }\end{array}$ & Infusão, in natura & Constipação & 12 \\
\hline Algodãozinho & $\begin{array}{l}\text { Cochlospermum regium } \\
\text { (Schrank) Pilg. }\end{array}$ & Folhas & Infusão, garrafada & $\begin{array}{l}\text { Inflamação e } \\
\text { depurativo do } \\
\text { sangue }\end{array}$ & 12 \\
\hline Barbatimão & $\begin{array}{l}\text { Stryphnodendron } \\
\text { adstringens (Mart.) } \\
\text { Coville }\end{array}$ & Cascas & Decocção, garrafada & $\begin{array}{l}\text { Inflamação, } \\
\text { cicatrização } \\
\text { e infecção na } \\
\text { bexiga }\end{array}$ & 11 \\
\hline
\end{tabular}




\begin{tabular}{|c|c|c|c|c|c|}
\hline Nome popular & Nome científico & Parte usada & Formas de uso & $\begin{array}{l}\text { Doenças mais } \\
\text { citadas }\end{array}$ & NC \\
\hline Lima & $\begin{array}{l}\text { Citrus aurantifolia } \\
\text { (Christm.) Swingle }\end{array}$ & Fruto & Infusão & $\begin{array}{l}\text { Calmante e } \\
\text { hipertensão }\end{array}$ & 11 \\
\hline $\begin{array}{l}\text { Hortelã-do- } \\
\text { campo }\end{array}$ & Hyptis cf. hirsuta Kunth & Folhas & Infusão & $\begin{array}{l}\text { Gripe, tosse e } \\
\text { verminose }\end{array}$ & 11 \\
\hline Angico & $\begin{array}{l}\text { Anadenanthera } \\
\text { colubrina (Vell.) Brenan }\end{array}$ & Cascas & Decocção & $\begin{array}{l}\text { Bronquite, } \\
\text { asma e tosse }\end{array}$ & 11 \\
\hline Urtiga & Solanum sp. L. & Folhas & Infusão & $\begin{array}{l}\text { Furúnculo e } \\
\text { inflamação }\end{array}$ & 10 \\
\hline $\begin{array}{l}\text { Erva-de- } \\
\text { passarinho }\end{array}$ & $\begin{array}{l}\text { Psittacanthus calyculatus } \\
\text { (D. C.) G. Don }\end{array}$ & Folhas & Infusão & $\begin{array}{l}\text { Dor e } \\
\text { pneumonia }\end{array}$ & 10 \\
\hline Fedegoso & $\begin{array}{l}\text { Senna occidentalis (L.) } \\
\text { Link }\end{array}$ & $\begin{array}{l}\text { Folhas e } \\
\text { caule }\end{array}$ & Infusão & $\begin{array}{l}\text { Tosse, dor e } \\
\text { verminose }\end{array}$ & 10 \\
\hline Buchinha & Luffa operculata Cogn. & $\begin{array}{l}\text { Folhas e } \\
\text { fruto }\end{array}$ & Infusão & $\begin{array}{l}\text { Anemia, rins e } \\
\text { abortivo }\end{array}$ & 10 \\
\hline Tamarindo & Tamarindus indica $\mathrm{L}$. & $\begin{array}{l}\text { Folhas e } \\
\text { fruto }\end{array}$ & Infusão, suco & $\begin{array}{l}\text { Dor de barriga, } \\
\text { laxante e } \\
\text { verminose }\end{array}$ & 9 \\
\hline Maracujá & Passiflora alata Curtis. & $\begin{array}{l}\text { Folhas e } \\
\text { fruto }\end{array}$ & Infusão, in natura & Calmante & 9 \\
\hline Cajá-manga & $\begin{array}{l}\text { Spondias dulcis } \\
\text { Parkinson }\end{array}$ & Fruto & Infusão, in natura & Coceira e sarna & 9 \\
\hline $\begin{array}{l}\text { Folha-da- } \\
\text { fortuna }\end{array}$ & $\begin{array}{l}\text { Kalanchoe pinnata } \\
\text { (Lam.) Pers. }\end{array}$ & Folhas e raiz & Maceração & $\begin{array}{l}\text { Alergia e } \\
\text { bronquite }\end{array}$ & 9 \\
\hline Mamona & Ricinus communis L. & $\begin{array}{l}\text { Folhas e } \\
\text { fruto }\end{array}$ & Garrafada & Cicatrização & 9 \\
\hline Marcela & $\begin{array}{l}\text { Achyrocline satureioides } \\
\text { (Lam.) DC. }\end{array}$ & Folhas & Infusão & Estômago & 9 \\
\hline $\begin{array}{l}\text { Caninha-do- } \\
\text { brejo }\end{array}$ & $\begin{array}{l}\text { Costus spicatus (Jacq.) } \\
\text { Sw. }\end{array}$ & Folhas & Infusão & $\begin{array}{l}\text { Diurético e } \\
\text { infecção na } \\
\text { bexiga }\end{array}$ & 9 \\
\hline Alfavaca & Ocimum gratissimum L. & Folhas & Infusão & Tosse e gripe & 8 \\
\hline Abacate & Persea americana Mill. & $\begin{array}{l}\text { Folhas e } \\
\text { fruto }\end{array}$ & Infusão, in natura & $\begin{array}{l}\text { Diurético e } \\
\text { hipertensão }\end{array}$ & 8 \\
\hline Pinhão-roxo & $\begin{array}{l}\text { Jatropha aff. } \\
\text { Gossypiifolia L. }\end{array}$ & Folhas & Maceração, tintura & $\begin{array}{l}\text { Cicatrização } \\
\text { e picada de } \\
\text { insetos/cobra }\end{array}$ & 8 \\
\hline $\begin{array}{l}\text { Losna/ } \\
\text { nervônica }\end{array}$ & Artemisia absinthium L. & Folhas & Infusão & $\begin{array}{l}\text { Estômago e } \\
\text { fígado }\end{array}$ & 8 \\
\hline Salsa & $\begin{array}{l}\text { Petroselinum crispum } \\
\text { (Mill.) Nym }\end{array}$ & Folhas & In natura & Gripe e tosse & 7 \\
\hline Anador & Justicia pectoralis Jacq. & Folhas & Infusão & Dor e febre & 7 \\
\hline Jenipapo & Genipa americana L. & Folhas & Infusão & $\begin{array}{l}\text { Bronquite, } \\
\text { diabetes e rins }\end{array}$ & 7 \\
\hline Malva & Malva sylvestris $\mathrm{L}$. & Folhas & Infusão & $\begin{array}{l}\text { Cicatrização e } \\
\text { inflamação }\end{array}$ & 7 \\
\hline Negramina & $\begin{array}{l}\text { Siparuna guianensis } \\
\text { Aubl. }\end{array}$ & Folhas & $\begin{array}{l}\text { Infusão, decocção, } \\
\text { outros }\end{array}$ & $\begin{array}{l}\text { Dor, febre e } \\
\text { resfriado }\end{array}$ & 7 \\
\hline
\end{tabular}




\begin{tabular}{|c|c|c|c|c|c|}
\hline Nome popular & Nome científico & Parte usada & Formas de uso & $\begin{array}{l}\text { Doenças mais } \\
\text { citadas }\end{array}$ & NC \\
\hline Melissa & Melissa officinalis L. & Folhas & Infusão & Calmante & 7 \\
\hline Sucupira & $\begin{array}{l}\text { Bowdichia virgilioides } \\
\text { Kunth }\end{array}$ & Semente & $\begin{array}{l}\text { Maceração, } \\
\text { garrafada }\end{array}$ & $\begin{array}{l}\text { Inflamação na } \\
\text { garganta, tosse, } \\
\text { verminose }\end{array}$ & 7 \\
\hline Carambola & Averrhoa carambola L. & $\begin{array}{l}\text { Folhas e } \\
\text { fruto }\end{array}$ & Infusão, in natura & $\begin{array}{l}\text { Hipertensão e } \\
\text { calmante }\end{array}$ & 7 \\
\hline Picão & Bidens pilosa $\mathrm{L}$. & Folhas & Infusão, decocção & $\begin{array}{l}\text { Icterícia e } \\
\text { hepatite }\end{array}$ & 7 \\
\hline Insulina & Cissus cissyoides L. & Folhas & Infusão & Diabetes & 7 \\
\hline Pata-de-vaca & Bauhinia divarigata $\mathrm{L}$. & Folhas & Infusão & Diabetes & 7 \\
\hline Arnica & Arnica chamissonis Less. & Folhas & In natura, tintura & $\begin{array}{l}\text { Cicatrizante, } \\
\text { inflamação e } \\
\text { infecção }\end{array}$ & 7 \\
\hline $\begin{array}{l}\text { Batatinha-do- } \\
\text { brejo }\end{array}$ & $\begin{array}{l}\text { Ipomoea asarifolia } \\
\text { (Desr.) Roem. \& Schult. }\end{array}$ & Tubérculo & Decocção & Verminose & 6 \\
\hline Juá & Solanum viarum Dunal. & Folhas & Infusão & Hemorroidas & 6 \\
\hline Graviola & Annona crassiflora Mart. & $\begin{array}{l}\text { Folhas e } \\
\text { fruto }\end{array}$ & Infusão, in natura & $\begin{array}{l}\text { Diabetes e } \\
\text { câncer }\end{array}$ & 6 \\
\hline $\begin{array}{l}\text { Chapéu-de- } \\
\text { couro }\end{array}$ & $\begin{array}{l}\text { Echinodorus } \\
\text { macrophyllus (Kuntze.) } \\
\text { Micheli }\end{array}$ & Folhas & Infusão & Estômago e rins & 6 \\
\hline Cancerosa & $\begin{array}{l}\text { Maytenus ilicifolia Mart. } \\
\text { ex Reissek }\end{array}$ & Folhas & Infusão & $\begin{array}{l}\text { Cicatrização e } \\
\text { estômago }\end{array}$ & 6 \\
\hline Erva-mate & $\begin{array}{l}\text { Ilex paraguariensis A. } \\
\text { St. Hil. }\end{array}$ & $\begin{array}{l}\text { Folhas e } \\
\text { caule }\end{array}$ & Decocção & Colesterol & 6 \\
\hline $\begin{array}{l}\text { Língua-de- } \\
\text { vaca }\end{array}$ & $\begin{array}{l}\text { Chaptalia integerrima } \\
\text { (Vell.) Burkart }\end{array}$ & Folhas & Infusão & Verminose & 5 \\
\hline Velame & $\begin{array}{l}\text { Macrosiphonia longiflora } \\
\text { (Desf.) Müll. Arg. }\end{array}$ & Folhas & Infusão & $\begin{array}{l}\text { Depurativo do } \\
\text { sangue e dores }\end{array}$ & 5 \\
\hline Orégano & Origanum vulgare L. & Folhas & Infusão, in natura & Estômago & 5 \\
\hline Guariroba & $\begin{array}{l}\text { Syagrus oleracea (Mart.) } \\
\text { Becc. }\end{array}$ & Folhas & Infusão & Rins & 5 \\
\hline Jacarandá & $\begin{array}{l}\text { Jacaranda mimosifolia } \\
\text { D. Don. }\end{array}$ & $\begin{array}{l}\text { Folhas e } \\
\text { caule }\end{array}$ & Infusão & $\begin{array}{l}\text { Infecção e } \\
\text { inflamação }\end{array}$ & 5 \\
\hline Amarra-pinto & Boerhavia coccinea $\mathrm{L}$. & $\begin{array}{l}\text { Folhas e } \\
\text { caule }\end{array}$ & Infusão & Dor na bexiga & 5 \\
\hline Piúva/ipê-roxo & $\begin{array}{l}\text { Handroanthus } \\
\text { impetiginosus (Mart.) } \\
\text { Mattos }\end{array}$ & Cascas & Decocção & Câncer e dor & 4 \\
\hline Figueirinha & Ficus pertusa L. f. & Folhas & Infusão & Estômago & 4 \\
\hline Guatambu & $\begin{array}{l}\text { Aspidosperma } \\
\text { tomentosum Mart. }\end{array}$ & Folhas & Infusão & Gastrite & 4 \\
\hline Beterraba & Beta vulgaris $\mathrm{L}$. & Raiz & In natura & Anemia & 4 \\
\hline
\end{tabular}




\begin{tabular}{|c|c|c|c|c|c|}
\hline Nome popular & Nome científico & Parte usada & Formas de uso & $\begin{array}{l}\text { Doenças mais } \\
\text { citadas }\end{array}$ & NC \\
\hline Amora & Rubus brasiliensis Mart. & $\begin{array}{l}\text { Folhas e } \\
\text { fruto }\end{array}$ & Infusão & $\begin{array}{l}\text { Cicatrizante, } \\
\text { inflamação e } \\
\text { queda de cabelo }\end{array}$ & 4 \\
\hline Raiz-de-bugre & $\begin{array}{l}\text { Cayaponia tayuya (Cell.) } \\
\text { Cogn. }\end{array}$ & Raiz & Decocção & $\begin{array}{l}\text { Dor e } \\
\text { depurativo do } \\
\text { sangue }\end{array}$ & 4 \\
\hline $\begin{array}{l}\text { Hortelã- } \\
\text { pimenta }\end{array}$ & Mentha x piperita $\mathrm{L}$. & Folhas & Infusão, in natura & $\begin{array}{l}\text { Bronquite, } \\
\text { gripe e tosse }\end{array}$ & 3 \\
\hline Chá-de-frade & Casearia silvestris Eichler & Folhas & Infusão & Dor e febre & 3 \\
\hline Jaborandi & Piper cuyabanum C. DC. & Folhas & Infusão & $\begin{array}{l}\text { Estômago } \\
\text { e queda de } \\
\text { cabelo }\end{array}$ & 3 \\
\hline Mangabeira & $\begin{array}{l}\text { Hancornia speciosa } \\
\text { Gomes }\end{array}$ & Folhas & Infusão & Estômago & 3 \\
\hline Hibisco & Hibiscus rosa-sinensis L. & Flor & Infusão & Dor & 3 \\
\hline Pitanga & $\begin{array}{l}\text { Eugenia pitanga (O. } \\
\text { Berg) Kiaersk. }\end{array}$ & Fruto & In natura & $\begin{array}{l}\text { Dor de garganta } \\
\text { e laxante }\end{array}$ & 3 \\
\hline Berinjela & Solanum melongena $\mathrm{L}$. & Fruto & Infusão, garrafada & Colesterol & 3 \\
\hline Urucum & Bixa orellana $\mathrm{L}$. & $\begin{array}{l}\text { Folhas e } \\
\text { sementes }\end{array}$ & Infusão, in natura & Colesterol & 3 \\
\hline Milho & Zea mays L. & $\begin{array}{l}\text { Folhas e } \\
\text { fruto }\end{array}$ & In natura & Bexiga e rins & 3 \\
\hline $\begin{array}{l}\text { Cipó-de- } \\
\text { galinha }\end{array}$ & Bauhinia glabra Jacq. & Folhas & Infusão & Diurético & 3 \\
\hline Jucá & Caesalpinea ferrea Mart. & Folhas & Infusão & $\begin{array}{l}\text { Diabetes e } \\
\text { febre }\end{array}$ & 3 \\
\hline Cambará & $\begin{array}{l}\text { Gochnatia polymorpha } \\
\text { Less. }\end{array}$ & Cascas & Decocção & Tosse e gripe & 3 \\
\hline $\mathrm{Nim}$ & $\begin{array}{l}\text { Azadirachta indica A. } \\
\text { Juss. }\end{array}$ & Folhas & Infusão & Diabetes & 2 \\
\hline Jequitibá & $\begin{array}{l}\text { Cariniana rubra Gardner } \\
\text { ex Miers }\end{array}$ & Folhas & Infusão & $\begin{array}{l}\text { Cicatrização, } \\
\text { bexiga e } \\
\text { inflamação }\end{array}$ & 2 \\
\hline Unha-de-gato & $\begin{array}{l}\text { Uncaria tomentosa } \\
\text { (Willd. ex Schult.) DC. }\end{array}$ & Folhas & Infusão & $\begin{array}{l}\text { Infecção e } \\
\text { inflamação }\end{array}$ & 2 \\
\hline Capim-sapé & $\begin{array}{l}\text { Imperata brasiliensis } \\
\text { Trin. }\end{array}$ & Folhas & Infusão & $\begin{array}{l}\text { Diabetes, dor } \\
\text { nos rins }\end{array}$ & 2 \\
\hline Fava & $\begin{array}{l}\text { Dimorphandra mollis } \\
\text { Benth. }\end{array}$ & Folhas e raiz & Infusão & $\begin{array}{l}\text { Bronquite e } \\
\text { pneumonia }\end{array}$ & 2 \\
\hline Cabaça & Crataeva tapia $\mathrm{L}$. & Folhas & Infusão & Tosse & 2 \\
\hline Cardo-santo & Argemone mexicana $\mathrm{L}$. & Folhas e raiz & Infusão & $\begin{array}{l}\text { Hipertensão e } \\
\text { gripe }\end{array}$ & 2 \\
\hline Cavalinha & Equisetum hyemale L. & Caule & Infusão & Diurético & 2 \\
\hline
\end{tabular}




\begin{tabular}{|c|c|c|c|c|c|}
\hline Nome popular & Nome científico & Parte usada & Formas de uso & $\begin{array}{l}\text { Doenças mais } \\
\text { citadas }\end{array}$ & NC \\
\hline Erva-mula & $\begin{array}{l}\text { Rudgea viburnoides } \\
\text { (Cham.) Benth }\end{array}$ & Folhas & Infusão & $\begin{array}{l}\text { Dor na coluna e } \\
\text { dor de dente }\end{array}$ & 1 \\
\hline Leiteiro & $\begin{array}{l}\text { Euphorbia heterophylla } \\
\text { L. (EPHHL) }\end{array}$ & Folhas & Infusão & $\begin{array}{l}\text { Bronquite, } \\
\text { asma e laxante }\end{array}$ & 1 \\
\hline $\begin{array}{l}\text { Bácimo-do- } \\
\text { campo }\end{array}$ & $\begin{array}{l}\text { Eremanthus exsuccus } \\
\text { (DC.) Baker }\end{array}$ & Folhas & Infusão & $\begin{array}{l}\text { Cicatrização e } \\
\text { dor muscular }\end{array}$ & 1 \\
\hline Contra-erva & Dorstenia contrajerva L. & Folhas & Infusão & Febre e dor & 1 \\
\hline Vick & Mentha spicata L. & Folhas & Infusão & $\begin{array}{l}\text { Bronquite, } \\
\text { gripe e tosse }\end{array}$ & 1 \\
\hline $\begin{array}{l}\text { Batata-de- } \\
\text { purga }\end{array}$ & $\begin{array}{l}\text { Ipomoea purga } \\
\text { (Wender.) Hayne }\end{array}$ & Rizoma & Decocção & $\begin{array}{l}\text { Inflamação, } \\
\text { diurética e } \\
\text { laxante }\end{array}$ & 1 \\
\hline Vergateso & $\begin{array}{l}\text { Anemopaegma arvense } \\
\text { (Vell.) Stellfeld }\end{array}$ & Folhas e raiz & Infusão & $\begin{array}{l}\text { Diurético e } \\
\text { afrodisíaco }\end{array}$ & 1 \\
\hline $\begin{array}{l}\text { Cana-de- } \\
\text { macaco }\end{array}$ & $\begin{array}{l}\text { Dichorisandra hexandra } \\
\text { (Aubl.) Standl. }\end{array}$ & Folhas e raiz & Infusão & Dor na coluna & 1 \\
\hline Mulher-pobre & $\begin{array}{l}\text { Dilodendron bipinnatum } \\
\text { Radlk. }\end{array}$ & $\begin{array}{l}\text { Folhas e } \\
\text { caule }\end{array}$ & Infusão & $\begin{array}{l}\text { Inflamação e } \\
\text { fraturas }\end{array}$ & 1 \\
\hline Pata-de-vaca & Bauhinia forficata Link & Folhas & Infusão & $\begin{array}{l}\text { Diurético e } \\
\text { diabetes }\end{array}$ & 1 \\
\hline Açafrão & Curcuma longa $\mathrm{L}$. & Semente & In natura & Inflamação & 1 \\
\hline Louro & Laurus nobilis L. & Folhas & Infusão & $\begin{array}{l}\text { Inflamação do } \\
\text { útero }\end{array}$ & 1 \\
\hline Tapera-velha & $\begin{array}{l}\text { Hyptis suaveolens (L.) } \\
\text { Poit. }\end{array}$ & Folhas & Infusão & $\begin{array}{l}\text { Constipação e } \\
\text { dor de barriga }\end{array}$ & 1 \\
\hline Sene & Cassia angustifolia Vahl. & Folhas & Infusão & Laxante & 1 \\
\hline $\begin{array}{l}\text { Cordão-de- } \\
\text { são-francisco }\end{array}$ & $\begin{array}{l}\text { Leonotis nepetifolia (L.) } \\
\text { R. Br. }\end{array}$ & Folhas & Infusão & $\begin{array}{l}\text { Cicatrizante e } \\
\text { febre }\end{array}$ & 1 \\
\hline Agrião & $\begin{array}{l}\text { Nasturtium officinale R. } \\
\text { Br. }\end{array}$ & Folhas & In natura & Tosse & 1 \\
\hline Fumo & Nicotiana tabacum L. & Folhas & In natura, infusão & $\begin{array}{l}\text { Inflamação e } \\
\text { verminose }\end{array}$ & 1 \\
\hline
\end{tabular}

Legenda: Outros (compressa, banho). NC: Número de citações.

Fonte: Próprios autores.

Quanto às indicações terapêuticas referidas pelos informantes, aquelas voltadas às patologias do sistema respiratório (349 citações) e aos problemas relacionados ao sistema gastrointestinal (177 citações) foram as mais citadas dentro da comunidade, representadas por 36 espécies e 18 espécies, respectivamente. Entre as doenças respiratórias, encontram-se: gripe, tosse, bronquite e pneumonia, representando o primeiro lugar no ranking de citações. Em segundo lugar, problemas gastrointestinais como gastrite, úlcera, dores e distúrbios estomacais, constipação e diarreia. Outro destaque foram as indicações de anti-inflamatórios e cicatrizantes, com 34 espécies utilizadas para essas finalidades. 
Os problemas geniturinários também foram citados (103 citações), representados por 18 espécies com destaque para as enfermidades renais e da bexiga (dores e finalidades diuréticas). Sobre os problemas de saúde relacionados neste estudo, Gonçalves e Pasa (2015) também encontraram resultados, sendo os mais expressivos: respiratórios, com 19\%; gastrointestinal, com 16\%; e geniturinário, com 15\%. Em outro estudo realizado por David e Pasa (2015), as autoras também relataram encontrar citações para problemas semelhantes, como geniturinários (22\%), respiratórios (20\%) e digestórios (18\%).

\section{CONSIDERAÇÕES FINAIS}

A importância dos estudos etnobotânicos realizados em comunidades, sejam eles tradicionais, sejam eles de saber local, permite a aproximação do pesquisador com a realidade dessas populações, resgatando o amplo conhecimento de vida adquirido pela transmissão de cultura e pelas experiências empíricas com a natureza.

A Comunidade Barreirinho preserva todos os seus costumes e hábitos tradicionais. O uso dos recursos vegetais, incluindo suas aplicações, evidencia a crença que a população tem diante da natureza, o seu conhecimento, conservação e preservação das plantas, tanto dos quintais como dos recursos disponíveis e utilizados da flora local para as diversas etnocategorias botânicas, principalmente como método alternativo para o tratamento de várias enfermidades e doenças mais comuns.

Esse resgate etnobotânico demonstrou que a comunidade local carrega um amplo conhecimento sobre plantas para fins terapêuticos e medicinais, representado pela etnofarmacologia, como estratégia de investigação das plantas, auxiliando no desenvolvimento dos estudos fitoterápicos e no desenvolvimento de fármacos, por agregar valor ao conhecimento e saber empírico.

\section{REFERÊNCIAS}

ALEXIADES, Miguel. Ethnobotany of the Ese Eja: Plants, health, and change in an Amazonian Society. 1999. 464 p. Tese (Doutorado em Filosofia) - The City University of New York. Disponível em: <http://citeseerx. ist.psu.edu/viewdoc/download?doi=10.1.1.452.5979\&rep=rep1\&type=pdf>. Acesso em: 19 ago. 2017.

AMARAL, Eni Aparecida; SILVA, Regildo Márcio Gonçalves. Avaliação da Toxidade Aguda de Angico (Anadenanthera falcata), Pau-Santo (Kilmeyera coreacea), Aroeira (Myracrodruon urundeuva) e Cipó-deSão-João (Pyrostegia venusta), por meio do bioensaio com Artemia salina. Perquirçre - Revista Eletrônica da Pesquisa, v. 5, n. 5, 2008. Disponível em: http://perquirere.unipam.edu.br/documents/23456/34929/ artigo_eni.pdf. Acesso em: 15 out. 2017.

ANGIOSPERM PHYLOGENY GROUP (APG IV). An update of the Angiosperm Phylogeny Group classification for the orders and families of flowering plants: APG IV. Botanical Journal of the Linnean Society, n. 181, p. 1-20, 2016. Disponível em: http://reflora.jbrj.gov.br/downloads/2016_GROUP_Botanical\%20Journal \%20of\%20the\%20Linnean\%20Society.pdf. Acesso em: 21 jun. 2017.

BARROS, Silvia Berlanga; DAVINO, Solange. Avaliação da toxicidade. In: OGA, Seizi; CAMARGO, Marcia Maria de Almeida; BATISTUZZO, José Antônio de Oliveira. (Org.). Fundamentos de toxicologia. 2. ed. São Paulo: Atheneu, 2003.

BARROS, A. T.; ANDRADE, T. D. M.; SILVA, M. J. R.; DINIZ, D. K. T.; SOUSA, K. N.; TRAJANO, L. L. Estudo do conhecimento das plantas de uso medicinal pelos alunos do sistema EJA de educação em dois municípios 
do interior da Paraíba. In: CONGRESSO INTERNACIONAL, 1., Patos, PB, Universidade Estadual da Paraíba (UEPB), 2010. Anais [...]. Cátedra Unesco, 2010. Disponível em: https://www.catedraunescoeja.com.br/icongresso-internacional/GT06_COM021.pdf. Acesso em: 25 set. 2017.

COSTA, Gilmar da; SILVA, Patrícia Sanches da. Tratamento bioenergético: estudo etnofarmacológico de plantas medicinais da Pastoral da Saúde Alternativa de Cotriguaçú, MT. Biodiversidade, v. 13, n. 1, p. 115-24, 2014. Disponível em: http://periodicoscientificos.ufmt.br/ojs/index.php/biodiversidade/article/ view/1544. Acesso em: 25 set. 2017.

DAVID, M.; PASA, M. C. As plantas medicinais e a etnobotânica em Várzea Grande, MT, Brasil. Interações, Campo Grande, MS, v. 16, n. 1, p. 97-108, 2015. Disponível em: https://www.scielo.br/pdf/inter/ v16n1/1518-7012-inter-16-01-0097.pdf. Acesso em: 25 set. 2017.

ELIZABETSKY, Elaine. Etnofarmacologia. Ciência e Cultura, v. 55, n. 3, p. 35-6, 2003. Disponível em: http:// cienciaecultura.bvs.br/scielo.php?script=sci_arttext\&pid=S0009-67252003000300021. Acesso em: 25 set. 2017.

FERREIRA, André Luis de Souza; BATISTA, Caio Augusto; PASA, Maria Corette. Uso de plantas medicinais na comunidade quilombola Mata Cavalo em Nossa Senhora do Livramento - MT, Brasil. Biodiversidade, v. 14, n. 1, p. 151-60, 2015. Disponível em: http://periodicoscientificos.ufmt.br/ojs/index.php/biodiversidade/ article/view/2258. Acesso em: 25 set. 2017.

GONÇALVES, Karina Gondolo; PASA, Maria Corette. A etnobotânica e as plantas medicinais na Comunidade Sucuri, Cuiabá, MT, Brasil. Interações, Campo Grande, MS, v. 16, n. 2, p. 245-256, 2015. Disponível em: http://www.scielo.br/pdf/inter/v16n2/1518-7012-inter-16- 2- 0245.pdf. Acesso em: 12 jul. 2017.

GUARIM NETO, Germano; CARVALHO, João Victor. Biodiversidade mato-grossense: as plantas e suas potencialidades. Cuiabá: Carlini \& Caniato, 2011.

GUARIM NETO, Germano; PASA, Maria Corette. Estudo Etnobotânico em uma área de Cerrado no Município de Acorizal, Mato Grosso. Flovet, v. 1, p. 5-32, 2009. Disponível em: http://periodicoscientificos.ufmt.br/ ojs/index.php/flovet/article/view/653. Acesso em: 30 jun. 2017.

GUARIM NETO, Germano; MACIEL, Marcia Regina Antunes. O saber local e os recursos vegetais em Juruena Mato Grosso. Mato Grosso: EdUFMT, 2008. 112p.

INSTITUTO BRASILEIRO DE GEOGRAFIA E ESTATÍSTICA. Censo Demográfico. Rio de Janeiro: IBGE, 2010. Disponível em: http://www.censo2010.ibge.gov.br/sinopse/index. php?uf=51\&dados=6. Acesso em: 12 mar. 2017.

MINAYO, Maria Cecilia de Souza. O desafio do conhecimento: pesquisa qualitativa em saúde. 10. ed. São Paulo: Hucitec, 2007.

MINAYO, Maria Cecilia de Souza. Pesquisa Social: teoria, método e criatividade. Petrópolis: Vozes, 1994.

MOREIRA, Rogério Pinto de Moura; GUARIM NETO, Germano. A flora medicinal dos quintais de Tangará da Serra, Mato Grosso, Brasil. Biodiversidade, v. 14, n. 1, p. 63-83, 2015. Disponível em: http:// periodicoscientificos.ufmt.br/ojs/index.php/biodiversidade/article/view/2252. Acesso em: 17 mar. 2017.

PASA, M.C. Etnobiologia de uma comunidade Ribeirinha no alto da bacia do rio Árica Açu, Cuiabá, Mato Grosso, Brasil. 2004. 174f. Tese (Doutorado em Ecologia e recursos naturais) Centro de ciências biológicas e da saúde, Universidade Federal de São Carlos, São Carlos. SP. Disponível em: https://repositorio.ufscar. br/bitstream/handle/ufscar/1721/TeseMCP.pdf?sequence=1\&isAllowed=y. Acesso em 12 abr. 2017. 
PASA, Maria Corette. Abordagem etnobotânica na Comunidade de Conceição-Açú, Mato Grosso, Brasil. Polibotânica, v. 31, p. 169-97, 2011. 186p. Disponível em: http://www.scielo.org.mx/scielo.php?pid=S140527682011000100011\&script=sci_abstract. Acesso em: 17 mar. 2017.

PASA, Maria Corette; DAVID, Margô; FIEBIG, Gabriela de Avila; NARDEZ, Taina Maiza Bilinski; MAZIERO, Edi Liane. A etnobotânica na comunidade quilombola em Nossa Senhora do Livramento. Mato Grosso, Brasil. Biodiversidade, v. 14, n. 2, p. 2-14, 2015. Disponível em: http://periodicoscientificos.ufmt.br/ojs/ index.php/biodiversidade/article/view/2889. Acesso em: 22 maio 2017.

PINTO, Erika de Paula Pedro; AMOROZO, Maria Christina de Mello; FURLAN, Antônio. Conhecimento popular sobre plantas medicinais em comunidades rurais de mata atlântica-Itacaré, BA, Brasil. Acta Botânica Brasílica, v. 20, n. 4, p. 751-62, 2006. Disponível em: http://www.scielo.br/scielo.php?script=sci_arttext \&pid=S0102-33062006000400001. Acesso em: 22 mai. 2017.

TOLEDO, Victor Manuel; BARRERA-BASSOLS, Narciso. A etnoecologia: uma ciência pós-normal que estuda as sabedorias tradicionais. Desenvolvimento e Meio Ambiente, v. 20, p. 31-45, 2009. Disponível em: https:// revistas.ufpr.br/made/article/view /14519/1.0948. Acesso em: 30 jun. 2017.

\section{Sobre os autores:}

André Luís de Souza Ferreira: Mestrado em Ciências Florestais e Ambientais pela Universidade Federal de Mato Grosso (UFMT), linha de pesquisa Análise e Gestão dos Recursos Naturais (Ecologia, Etnobotânica e Etnofarmacologia). Graduação em Ciências Biológicas pela UFMT e em Tecnologia em Gestão Ambiental pela Universidade Norte do Paraná. E-mail: aluissouza@hotmail.com, Orcid: http://orcid.org/0000-0002-0178-2687

Maria Corette Pasa: Pós-Doutorado em Etnofarmacobotânica na Cultura de Comunidades Afrodescendentes - Brasil/Europa/África. Doutorado em Ciências - Ecologia e Recursos Naturais pela Universidade Federal de São Carlos (UFSCar). Mestrado em Ecologia e Conservação da Biodiversidade pela Universidade Federal de Mato Grosso (UFMT). Professora da Classe Associado do Departamento de Botânica e Ecologia - Instituto de Biociências da UFMT. Editora-chefe dos Periódicos Biodiversidade e Flovet - Flora, Vegetação e Etnobotânica da UFMT. Líder do Grupo de Pesquisa Estudando o Cerrado (Escer) - CNPq/CAPES. Membro de DGPs com certificação nacional e internacional IVR (Inteligência Vibracional Reversa) pela Universidade Federal de Santa Catarina (UFSC). E-mail: pasamc@brturbo.com.br, Orcid: http://orcid.org/0000-0001-5304-5294

Cecília Verônica Nunez: Pós-doutorado em Química Orgânica (Produtos Naturais) pela Universidade de São Paulo (USP), São Carlos, e em Farmacognosia pela Université de Lille-2, Droit et Santé, França. Doutorado em Química Orgânica (Produtos Naturais) pela USP. Mestrado em Química Orgânica (Produtos Naturais) pela USP. Graduação em Química pela Universidade Mackenzie. Tecnologista senior do Instituto Nacional de Pesquisas da Amazônia (Inpa); professora/ orientadora permanente dos Programas de Pós-Graduação em Biotecnologia da Universidade Federal do Amazonas (Ufam), Biotecnologia da Universidade do Estado do Amazonas (UEA/ Inpa) e Botânica (Inpa); professora/orientadora colaboradora do Programa de Pós-Graduação em Química na Ufam/Inpa. Editora das revistas Fitos e Journal of Botany Research. E-mail: cvnunez@gmail.com, Orcid: http://orcid.org/0000-0003-3400-9508 